\title{
Redes Sociais: O grupo como suporte para imigrantes brasileiras em Portugal
}

\author{
Social Networks: the group as a support for brazilian \\ immigrant women in portugal
}

Eliany Nazaré Oliveira66

\section{Resumo}

Este artigo constitui um relato de experiência sobre a criação e administração de um grupo nas redes sociais para imigrantes brasileiras em Portugal. A convivência no mundo virtual é uma realidade no século XXI. As novas tecnologias contribuem de forma significativa para aproximação de pessoas e grupos. As redes sociais podem ser consideradas um espaço privilegiado para comunicação e interação. O objetivo deste artigo é descrever o processo de organização, criação e administração do grupo "Brasileiras que Vivem em Portugal" no Facebook. A experiência demostrou sua utilidade e seus benefícios para quem se encontra em outro país e necessita de informações, camaradagem, dividir experiências, pertencer a um grupo étnico e apoio para inserção no mercado de trabalho. O espaço também é favorável para o desenvolvimento de pesquisa, já que pode agregar indivíduos com as características do público-alvo definido pelos pesquisadores. Assim, o grupo demonstrou ser um potente suporte nas redes sociais para imigrantes, contribuindo para sua integração e sobrevivência nesse cenário.

Palavras-chave: Imigração. Redes sociais. Mulher. Portugal.

\section{Abstract}

This article is an experience report on the creation and administration of a group on the social networks for Brazilian immigrant women in Portugal. Interaction in the virtual world is a reality in the $21^{\text {st }}$ century. The new technologies significantly contribute to bring people and groups closer. Social networks may be regarded as a privileged space for communication and interaction. This article aims to

66 Professora da Universidade Estadual Vale do Acaraú (UVA) - Ceará - Brasil; ORCID: https://orcid.org/0000-0002-6408-7243; Email: elianyy@hotmail.com 
describe the process of organizing, creating, and administrating the group "Brazilian women living in Portugal" on the Facebook. The experience has shown its usefulness and benefits for those who live abroad and need information, fellowship, sharing of experiences, belonging to an ethnic group, and support to enter the labor market. The space is also favorable for conducting research, as it can bring together individuals with characteristics of the target audience defined by the researchers. Thus, the group proved to be a powerful support on the social networks for immigrants, contributing to their interconnection and survival in this scenario.

Keywords: Immigration. Social networks. Women. Portugal.

\section{Introdução}

A migração pode ser considerada um dos maiores desafios de Saúde Pública em nivel mundial. Nesse contexto, há uma reconhecida necessidade de compreender a movimentação da população e seu impacto, seja nos países (de acolhimento, trânsito ou origem) ou nas populações (migrantes ou nativos) (DIAS; GONÇALVES, 2007).

Os diversos problemas sociais e econômicos enfrentados por parte da população no contexto histórico brasileiro têm consequências até os dias atuais. Muitos buscam uma vida melhor em outros paises. Cerca de 500 mil brasileiros residem no exterior (BRASIL, 2013).

São vários os motivos para imigrar ou migrar, que podem ser influenciados pelas condições socioeconômicas, pelo contexto político e pelas catástrofes naturais. Em geral, é possivel indicar que as motivações se relacionam a uma nova possibilidade de vida, melhores oportunidades de emprego, benefícios financeiros ou fuga de problemas ambientais, políticos e sociais. Os imigrantes que chegam a um novo país vivenciam situações conflituosas. Com frequência, são vistos com certa desconfiança ou até como uma ameaça pela comunidade que os recebe, sobretudo quando seu status é ilegal. Não raro, há receio de que concorrerão com a comunidade local pelos serviços públicos ou por postos de trabalho. Logo, a imigração e a migração implicam contato com novas culturas, 
diferentes maneiras de pensar e distintas crenças, fazendo surgir dificuldades de adaptação e problemas de saúde física e mental (WALDMAN, 2011).

Segundo Malheiros (2007), organizador da coletânea Imigração brasileira em Portugal, atualmente os brasileiros tornaram-se o maior grupo formal e contabilizado de estrangeiros no país. Mesmo considerando os estrangeiros com status ilegal e aqueles que obtiveram nacionalidade portuguesa, os brasileiros ocupam a primeira posição no ranking de grupos étnicos de origem não nacional.

Portugal assistiu a um paulatino crescimento da feminilização do contingente migratório e da participação das migrantes no mercado de trabalho. Não se deve esquecer que está em curso um processo de flexibilização e precarização do trabalho e que, mesmo com as significativas mudanças para diminuir as diferenças entre homens e mulheres, tanto do ponto de vista das áreas de atuação como da remuneração, em geral, observa-se a feminilização de campos profissionais menos prestigiados e há evidentes desvantagens salariais em comparação aos homens. A divisão sexual do trabalho contemporâneo somase a uma distribuição desigual de funções entre migrantes e não migrantes ou entre o grupo etnicamente dominante e as minorias étnicas, estabelecendo posições ou nichos de emprego para indivíduos com determinado perfil. Em Portugal, observa-se uma clara etnicização do trabalho doméstico e das empresas de limpeza (MENDONÇA, 2007).

Segundo dados do Serviço de Estrangeiros e Fronteiras (SEF, 2013), naquele ano, a população brasileira com vistos oficiais em Portugal totalizou 87.493 indivíduos (53.537 mulheres e 33.956 homens). Vale ressaltar que esses dados referem-se aos indivíduos em situação legal, sem estimar a quantidade real de brasileiros que vivem no país, uma vez que muitos se encontram em situação ilegal. Em 2015, o Itamaraty contabilizou 162.190 brasileiros residentes em Portugal, o que demonstra que o processo migratório Brasil-Portugal continua crescente.

Este artigo relata a experiência da criação de um grupo de suporte e apoio a imigrantes brasileiras em Portugal. Esse grupo também constitui uma ferramenta de pesquisa em nível de pós-doutorado na Faculdade de Psicologia e 
Ciências da Educação da Universidade do Porto, intitulada "Estado de Saúde e Qualidade de Vida de Imigrantes Brasileiras em Portugal". Esse espaço mostrouse um importante meio de comunicação entre os pesquisadores e as brasileiras que vivem no país. Além da coleta de dados de pesquisa, o grupo também tem por objetivo agregar mulheres de nacionalidade brasileira para troca de experiências, informações e discussão acerca das seguintes temáticas: saúde física, mental e reprodutiva, violência doméstica e outras sugeridas pelas integrantes.

As redes sociais representam uma importante estratégia de comunicação nos dias atuais, facilitando a obtenção de informações, pelos imigrantes, sobre tudo o que ocorre em seu novo local de residência. Desse modo, os indivíduos podem compensar situações de acesso limitado a notícias e assuntos específicos.

Segundo Vermelho, Velho e Bertoncello (2015), a tecnologia das redes sociais digitais (RSD) foi pensada, idealizada e construida para proporcionar relações horizontalizadas, sob a égide de um sistema fortemente alicerçado na verticalidade. Nesse sentido, muito mais que uma tecnologia da moda, as RSD podem responder a anseios humanos e podem ser elementos de tensão na sociedade atual. Manifestações organizadas pela rede são noticiadas com frequência, demonstrando seu potencial de mobilização social.

Nesse cenário, este artigo descreve a experiência da criação e administração de um grupo no Facebook para imigrantes brasileiras que vivem em Portugal.

\section{Motivação e justificativas para um grupo nas redes sociais}

O curso de pós-doutorado na Faculdade de Psicologia e Ciências da Educação da Universidade do Porto, em Portugal, colocou um dos autores deste artigo na posição de imigrante do sexo feminino, deslocando-se de Sobral-CE, Brasil, onde atua como professora universitária desde 1994. 
Na condição de imigrante e com a necessidade de encontrar imigrantes de mesma nacionalidade em seu destino, a criação do grupo "Brasileiras que Vivem em Portugal" mostrou-se o melhor caminho para alcançar os objetivos de pesquisa, além de proporcionar informações e contatos locais relevantes para uma pessoa recém-instada no país.

As redes sociais constituem um conjunto complexo de inter-relações que se dinamizam. Pode-se dizer que o ser humano vem estreitando suas relações e tornando-se cada vez mais comunicativo a partir de novos processos virtuais, que influenciam o comportamento tanto de indivíduos como de coletivos. A ação humana é afetada pelas relações sociais nas quais os agentes estão imersos, que proporcionam redes de solidariedade local no combate à exclusão social (MIZRUCHI, 2006).

As redes sociais mostram-se caminhos rápidos e eficientes de comunicação e interação social. Podem ser acessadas por meio de computadores, telefones celulares e tablets, com contato em tempo real, o que facilita o processo relacional, tendo em vista que as pessoas sempre tiveram como essência de vida a interação com a sociedade e com outros indivíduos.

Nesse cenário, comunicação virtual dentro de determinado grupo, os critérios de inclusão foram: ser mulher, de origem brasileira e residente em Portugal. O grupo constituiu uma estratégia para proporcionar redução do isolamento, suporte e apoio a esse público específico. Vale ressaltar que foram identificados diversos grupos no Facebook que poderiam oferecer dados relevantes à pesquisa em questão, porém, nenhum com potencial para abordar em detalhe temas relativo à saúde física, mental e reprodutiva, à violência doméstica e a outros assuntos específicos de interesse feminino.

As principais motivações para criação do grupo foram: a necessidade de localizar e convidar imigrantes brasileiras em Portugal a participar da pesquisa "Estado de Saúde e Qualidade de Vida de Imigrantes Brasileiras em Portugal" e a possibilidade do grupo criado em uma rede social tornar-se uma ferramenta de apoio, suporte e troca de informações e experiências entre as integrantes. 


\section{Imagem e identidade do grupo}

A imagem e as representações da mulher brasileira em Portugal ainda se mostram negativas. Segundo Correia (2014), com esse complexo processo de estereotipização discursiva da mulher e de recorrente xenofobia, foi verificado que Portugal, com base no impulso proporcionado pelos fundos comunitários, é um país de acolhimento de imigrantes atraídos pelo desenvolvimento econômico.

Correia (2014) contextualiza de forma clara o caso das "Mães de Bragança", primeiro exemplo para a discussão do discurso da mídia sobre a mulher brasileira. Um foco de tensão germinava desde 2003 no distrito de Bragança. O detonador do conflito foi a presença de prostitutas trabalhando em "clubes de dança" em toda a cidade, que atraíam homens de todas as idades e classes sociais e provocaram a contestação de um movimento feminino denominado "Mães de Bragança" - estas cansadas de ver seus maridos gastarem dinheiro com as meninas.

Uma vez definido o cenário no qual o grupo seria criado, a ideia era distanciar-se dessa imagem negativa da mulher brasileira, estabelecendo uma imagem de força e de luta que a representasse adequadamente, um símbolo de orgulho. Partindo desse pressuposto foi criada para o grupo a imagem ilustrada pela Figura 1.

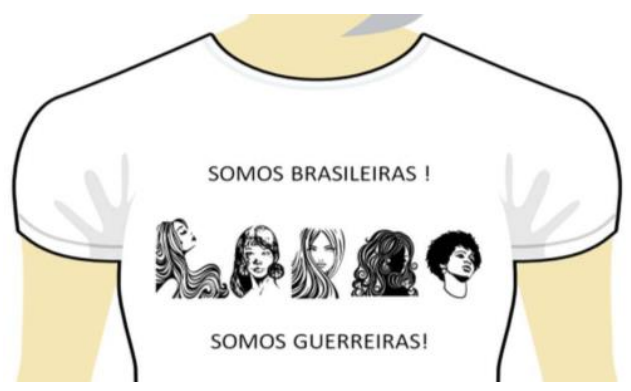

Figura 1 Logomarca do grupo "Brasileiras que Vivem em Portugal" no Facebook. Fonte: Elaborada pelos autores. 
A definição de pessoa guerreira, batalhadora, que luta, é forte e capaz de vencer os desafios, aquela que não desiste foi decisiva para tematizar a logomarca do grupo criado, tendo em vista o contexto histórico e a atual imagem da mulher brasileira em Portugal. As frases representativas do grupo não foram selecionadas ao acaso, o objetivo é, de fato, promover um sentimento de pertença e nacionalidade muitas vezes não observado em outro país.

Seguimos as orientações de Jacques (1998), ao oferecer pistas acerca das identidades migratórias. No estudo do autor, a representação dos migrantes brasileiros pela sociedade portuguesa em seu território, projetada no material jornalístico analisado, contempla uma atitude mais favorável e menos discriminatória do que a manifesta em relação às demais comunidades migrantes, principalmente as originárias de países africanos de língua portuguesa. Estas são objeto de hostilidade, associada à discriminação racial e socioeconômica, embora menos frequente e intensa do que a observada em outros países europeus.

A criação da logomarca para o grupo foi intencional e inspirada no estudo "Identidades migratórias", de Monteiro Neto (1985), que evidencia a necessidade do fortalecimento dessa identidade pessoal, em geral determinada pela situação migratória (poupança, trabalho, solidão). A afirmação da nacionalidade pode ser uma forma de evitar a ruptura total com o país de origem e um dos caminhos para o aumento da autoestima do imigrante, que se percebe inferior ou rejeitado no novo espaço em que vive.

O processo migratório influencia de maneira significativa a saúde física e mental do imigrante. De acordo com Monteiro Neto (2012), Portugal é atípico, dado que se trata de um país de emigração e imigração, com uma população imigrante que apresenta pequena distância em relação ao seu contexto cultural e uma população nacional caracterizada por atitudes positivas e protetoras perante os imigrantes. Um contraponto às ideias de Monteiro Neto (2012) provém de Elhajji e Malerba (2016): o migrante se revela, então, um perfeito reflexo diferencial da maioria e "normalidade"; um catalisador da diferença. A presença do estrangeiro tem, pois, esse potencial de provocar no observador, estranheza e 
estranhamento - seja de modo positivo (maravilhamento e fascínio) ou negativo (repulsa e medo).

Nesse contexto, a criação de uma imagem positiva para o grupo atende a dois objetivos: o primeiro vai ao encontro das necessidades das imigrantes brasileiras, que podem vislumbrar uma perspectiva afirmativa de sua condição étnica e de gênero, gerando, assim, um sentimento de pertencimento; já o segundo constitui uma mensagem à população receptora, enfatizando as características de um povo destemido e trabalhador.

\title{
Grupo "Brasileiras que vivem em Portugal"
}

Esse grupo foi criado no Facebook em março de 2016. Para seu efetivo funcionamento, diversas estratégias foram desenvolvidas. Depois do contato com outros grupos de nacionalidade brasileira, os convites foram enviados para o público desejado.

O Facebook é uma rede social que possibilita que uma pessoa, uma entidade ou um grupo poste seu perfil na internet para divulgar dados pessoais, com fotos, vídeos, links e notas, adicionando, para efeitos de correspondência virtual, outros usuários que são aceitos como "amigos".

O convite enviado consistia em um texto curto sobre os objetivos do grupo e os critérios de inclusão. Eis o texto integral do convite:

\begin{abstract}
VENHA PARTICIPAR DO GRUPO "BRASILEIRAS QUE VIVEM EM PORTUGAL"! Este grupo foi criado por Eliany Oliveira, que desenvolve Pós-Doutorado na Universidade do Porto, com sua pesquisa: ESTADO DE SAÚDE E QUALIDADE DE VIDA DE IMIGRANTES BRASILEIRAS EM PORTUGAL. Será um importante diagnóstico dessa situação para fomentar e sugerir políticas de apoio e proteção às brasileiras que vivem em Portugal. Além da pesquisa, o grupo pretende agregar mulheres brasileiras para discutir os temas: saúde física, mental e reprodutiva, sexualidade, violência contra as mulheres etc.
\end{abstract}

O link para acesso ao grupo foi incluido logo abaixo. Vale ressaltar que a logomarca do grupo aparecia no corpo do convite. 
Na primeira semana após o lançamento do grupo, ele já totalizava mais de 300 participantes. Além dos convites enviados para outros grupos de brasileiros, internamente, foram criadas algumas campanhas: a) Desafio da semana! Convide três amigas brasileiras para nosso grupo; b) Fale sobre este grupo com suas amigas brasileiras; c) Você tem amigas brasileiras que não estão neste grupo?

Nos dois primeiros meses do grupo, revisitamos os outros grupos dentre os quais foram enviados os convites todos os dias e curtimos nosso próprio convite, para que ele fosse visualizado novamente no topo da página, já que esses espaços virtuais são muito dinâmicos, eles contêm muitas postagens e as mais antigas não são visualizadas de um dia para o outro. Assim, a estratégia de curtir os convites já enviados resultou em uma grande quantidade de visualizações e diversas adesões ao nosso grupo.

No segundo mês do grupo, chegamos a 1.000 integrantes. Então, o grande desafio era manter o grupo ativo, vivo, com os objetivos propostos.

O ponto central para proporcionar vida ao grupo, além da pesquisa proposta pelos autores deste artigo, encontra ressonância em Elhaiji e Malerba (2016), que definiram a situação do imigrante. Via de regra, os migrantes são minoritários; quantitativamente menores em relação aos grupos nacionais, étnicos ou culturais que dominam numérica e politicamente a sociedade de acolhimento. Tal debilidade ou precariedade quantitativa resulta, com frequência, em condição e/ou estatuto social e político de subalternidade. O que, não raro, resulta em diversas formas de discriminação, racismo, xenofobia, opressão ou estigmatização do grupo minoritário e de seus membros.

O tema do primeiro fórum de discussão no grupo dizia respeito ao que era mais latente e percebido não só nos depoimentos de muitas brasileiras, mas na literatura disponivel: "Você já sofreu algum tipo de violência/discriminação em Portugal? Se sua resposta foi afirmativa, conte-nos o contexto vivido e as formas de enfrentamento utilizadas para superar a situação".

Durante duas semanas, esse espaço foi ocupado por relatos de diversas formas de violação de direitos e de discriminação. Os relatos são contundentes, indo ao encontro do que registram tanto a literatura relevante como os diálogos 
informais. Vale ressaltar que o fórum com essa temática permanece aberto, pois sempre há necessidade de falar sobre a violência e o preconceito no contexto dos imigrantes.

A administração do grupo observou que era muito mais fácil para as participantes descrever a situação de violência/discriminação vivenciada, pois a maioria apresentou dificuldade de comentar as formas de enfrentamento adotadas para superá-la. A coordenação do grupo assumiu papel fundamental ao estimular os relatos acerca das formas de superação do problema, pois essa é a essência de um grupo: apreender, apoiar, trocar informações, inspirar e até descobrir que a situação vivenciada por um membro não é algo isolado, que muitas pessoas com características similares também podem ter vivenciado tal constrangimento ou situação inadequada. Com essa função, acredita-se que o grupo tem servido como espaço terapêutico, já que possibilita o desabafo e, ao mesmo tempo, proporciona suporte e troca de experiências para o enfrentamento de determinadas situações.

A criação do grupo e as formas de comunicação nesse espaço corroboram a proposta de Elhajji e Malerba (2016): comunidade e comunicação remetem à mesma raiz etimológica e apontam o mesmo horizonte filosófico. Comunicar, formar uma comunidade ou entrar em comunhão implicam o mesmo gesto existencial de troca, partilha, participação, contribuição, aproximação e vinculação. Uma comunidade é, portanto, um conjunto de sentidos, o lugar (físico/territorial ou simbólico/imaginário) onde é produzido, veiculado e compartilhado o sentido comum ao corpo do grupo em sua totalidade reflexiva. Se a comunicação é um processo de produção de sentido, a comunidade é o lócus em que esse sentido é construido, transmitido, trocado, codificado e decodificado. Vale lembrar que, dentre as principais atribuições de natureza social e política intrinsecas à comunicação grupal, temos, em primeiro lugar, seu caráter discursivo responsável pela enunciação e manutenção da identidade coletiva.

O grupo segue com fóruns de discussão nos quais o principal objetivo é a troca de experiências e o auxílio mútuo. O tema mais recente na data em que 
este artigo foi redigido era: "SER BRASILEIRA E VIVER EM PORTUGAL - Comente, de forma resumida, o que significa para você ser mulher brasileira e viver em Portugal".

Os depoimentos são espontâneos, alguns com pontos negativos, destacando aspectos discriminatórios, outros com pontos positivos, revelando uma face do enraizamento, da qualidade de vida almejada e alcançada no país de acolhimento.

O espaço grupal recebeu importante apoio e fortalecimento depois das parcerias firmadas com a Associação Mais Brasil; a Embaixada do Brasil em Lisboa; a Associação Internacional Luso-Brasileira; o Consulado-Geral do Brasil no Faro; o Consulado-Geral do Brasil no Porto; e o Conselho de Cidadãs e Cidadãos. Essas entidades divulgaram o grupo em suas páginas no Facebook e ampliaram essa divulgação fora da internet, por meio de cartazes e panfletos impressos. As instituições brasileiras que atuam fora do país representando ou atuando em prol do imigrante brasileiro, em geral, promovem um sentimento de pertencimento e identidade com a nacionalidade. Nesse sentido, depois da parceria com essas instituições, a adesão ao grupo e à pesquisa cresceu de forma significativa.

Assim, com mais de 1.000 participantes, o grupo vem se estruturando. Vale ressaltar os desejos e anseios das brasileiras que participam do espaço grupal. Suas principais demandas são: oferta de trabalho autônomo - confecção de bolos e salgados, organização de festas, serviços na área de beleza e estética; apoio para a abertura de conta bancária e contratação de seguro; venda de bijuteria; apoio para transferência bancária, eventos de pequeno porte etc.

Peixoto e Figueiredo (2007) já alertavam que a incorporação dos imigrantes ao mercado de trabalho não depende apenas de suas estratégias individuais nem de critérios dos empregadores. Numerosos outros agentes, individuais e institucionais, estão envolvidos no processo e procedem à adequação entre procura e oferta de trabalho. Além desses, um dos principais veículos de incorporação laboral são as redes sociais. No plano "informal" - conterrâneos, 
familiares e amigos -, as redes sociais são responsáveis por canalizar informações e proporcionar suporte aos migrantes.

Em muitos casos, as participantes do grupo apenas postam um anúncio descrevendo suas habilidades e solicitando ajuda para inserção no mercado de trabalho. Algumas são mais sintéticas e diretas, postam um pedido de ajuda para encontrar trabalho em qualquer setor.

Alguns estudos sobre migração e mercado de trabalho em Portugal apontam que o grande contraste entre os segmentos profissionais que os imigrantes brasileiros ocuparam, ao longo do tempo, não tem apresentado correspondência com a variação de seu nível de qualificação. Tudo indica que a qualificação dos imigrantes brasileiros permanece acima da média da população portuguesa, ou seja, sua qualificação encontra-se acima dos requisitos dos postos profissionais que ocupam no mercado de trabalho (PEIXOTO; FIGUEIREDO, 2007).

Ainda sobre o mercado de trabalho e os imigrantes em Portugal, segundo Costa (2009), a visibilidade social que a questão imigratória adquiriu, principalmente no novo milénio, começa a receber especial atenção nos estudos das mais diversas entidades. Ela resulta do grande contingente de imigrantes no mercado de trabalho português, sobretudo o de origem brasileira. Essas pessoas têm alimentado os setores de atividade fortemente consumidores de mão de obra pouco qualificada, destacando-se a construção civil, as obras públicas e os serviços de limpeza. O desemprego é mais elevado no sexo feminino, com 41,1\%, atingindo $35,4 \%$ do sexo masculino. Mais da metade das ucranianas $(51,9 \%)$ estavam desempregadas antes de vir para Portugal. As brasileiras apresentavam menor taxa de desemprego (24,8\%), enquanto entre as guineenses a taxa era de $28,4 \%$.

Peixoto e Egreja (2012) identificam as redes sociais como um dos caminhos de imigrantes para encontrar trabalho. Em primeiro lugar, as redes sociais são mais explicativas do que os outros meios para a obtenção de emprego em Portugal. O apoio das redes inclui o recurso a amigos brasileiros, familiares e portugueses. Outro meio com dimensão importante é a própria iniciativa. 
Contudo, é provável que mesmo esta só seja acionada depois do acesso a informações confiáveis junto a outros contatos. Nesse ponto, é relevante, ainda, a rapidez com que o primeiro emprego é obtido. A grande maioria dos imigrantes não ingressa no país com um contrato de trabalho, mas como turista, e só mais tarde procura regularizar sua permanência. Isso demonstra o enorme poder das redes (e da própria iniciativa) no campo das migrações internacionais, não obstante os obstáculos à circulação do trabalho.

Nosso grupo também apresenta outra função: muitas brasileiras buscavam amizade e troca de experiências. Grande parte delas, em sua apresentação, revelou ser casada com um português e viver muito bem neste país, e demonstrou saudosismo em relação à sua terra e desejo de fazer novas amizades. Mais uma vez, identifica-se a busca de proximidade com suas origens, contato com sua cultura, o que se pode indicar como identidade social.

Para Tajfel (1981), a identidade social é a parcela do autoconceito de um indivíduo que deriva da consciência de sua pertença a determinado grupo social, junto com o significado emocional e o valor associado a essa pertença. Pertencer a um grupo é algo muito significativo para as pessoas, principalmente quando se encontram na condição de imigrantes. Seus desdobramentos influenciam sobremaneira a saúde física e mental dos que deixaram sua pátria para viver em outro país.

Ao final deste relato de experiência sobre a criação e administração de um grupo de imigrantes brasileiras em Portugal, é imprescindivel destacar a importância do papel do administrador de tal espaço. Trata-se de uma função que requer trabalho diário, dedicação e zelo, pois as pessoas que buscam o grupo apresentam suas próprias demandas, em geral, relacionadas à função que desempenham. Nesse sentido, segue uma lista com as tarefas realizadas em frequência diária: aceitar solicitações de entrada; aprovar postagem depois de analisar seu conteúdo; enviar mensagem de boas-vindas aos novos membros; responder perguntas enviadas diretamente aos administradores; complementar informações oferecidas; participar dos debates de forma apaziguadora; e mediar 
eventual conflito no espaço. Para o efetivo desenvolvimento do grupo, o papel do administrador é fundamental.

Assim, o grupo seguia ativo na data em que este artigo foi redigido; vale relembrar seus dois grandes objetivos: 1) servir de base para pesquisa em nível de pós-doutorado na Faculdade de Psicologia e Ciências da Educação da Universidade do Porto, intitulada "Estado de Saúde e Qualidade de Vida de Imigrantes Brasileiras em Portugal"; e 2) constituir ferramenta de apoio e suporte virtual para brasileiras que vivem em Portugal.

\section{Considerações finais}

A convivência no mundo virtual é uma realidade no século XXI. As novas tecnologias contribuem de forma significativa para a aproximação entre pessoas e grupos. As redes sociais podem ser consideradas um espaço privilegiado para se relacionar. Os ambientes virtuais são promissores para agregar pessoas e promover integração virtual, contribuindo de modo incisivo com os processos migratórios. O espaço também se mostra favorável para o desenvolvimento de pesquisa, já que facilita o contato com o público-alvo definido pelos pesquisadores - no caso relatado, brasileiras que vivem em Portugal.

A experiência demostrou sua utilidade e seus benefícios para quem se encontra em outro país e necessita de informações, camaradagem, dividir experiências, pertencer a um grupo étnico e apoio para inserção no mercado de trabalho. O grupo mostrou-se um potente suporte virtual para imigrantes, contribuindo com sua busca de uma vida melhor em outro país.

\section{Referências}

BRASIL. Brasileiros no mundo. 2013. Disponivel em: <http://www.brasileirosnomundo.itamaraty.gov.br/a-comunidade/estimativaspopulacionais-das-comunidades/estimativas-populacionais-das-comunidadesbrasileiras-no-mundo-2013/estimativas-2013.pdf . Acesso em: 30 jun. 2016. 
CORREIA, J. C. Dez anos depois de Bragança, a representação da mulher brasileira nos media. Verso e Reverso, São Leopoldo, v. 28, n. 69, p. 186-192, 2014. Disponivel em: <file:///D:/65-27477-1-PB.pdf>. Acesso em: 1 jul. 2016.

COSTA, P. Imigração em Portugal: tendências recentes, os imigrantes guineenses, ucranianos e brasileiros no mercado de trabalho português. Cadernos do Curso de Doutoramento em Geografia, FLUP, Porto, v. 1, p. 117-140, 2009. Disponivel em: <http://ler.letras.up.pt/uploads/ficheiros/769o.pdf $\geq$. Acesso em: $1^{\circ}$ jul. 2016.

DIAS, S.; GONÇALVES, A. Migração e saúde. Migrações, Lisboa, v. 1, p. 15-26, 2007. Disponivel em:

<http://www.uc.pt/fluc/gigs/GeoHealthS/doc_apoio/migracoes_e_saude.pdf>. Acesso em: 30 jun. 2016.

ELHAJJI, M.; MALERBA, J. P. Dos usos comunitários da webradiofonia no contexto migratório transnacional. Revista Interdisciplinar da Mobilidade Humana, Brasilia, v. 24, n. 46, p. 109-127, 2016. Disponivel em: <http://www.csem.org.br/remhu/index.php/remhu/article/view/571 2 . Acesso em: $1^{\circ}$ jul. 2016.

JACQUES, M. G. C. Identidades migratórias. Porto: Universidade Aberta de Portugal, 1998. (Relatório de pesquisa de pós-doutorado).

MALHEIROS, J. M. Os brasileiros em Portugal: a sintese do que sabemos. In: MALHEIROS, J. M. (Org.). Imigração brasileira em Portugal. Lisboa: ACIDI, 2007. p. 11-37. (Coleção Comunidade, n. 1).

MENDONÇA, L. F. M. Experiências de vida e formas de integração das imigrantes brasileiras em Portugal. 2007. Disponivel em: <http:// www.ceg.ul.pt/metropolis2006/WorkshopPresentations/Gulbenkian/LucianaMe ndonca_Paper_metropolis2006.pdf>. Acesso em: $1^{\circ}$ jul. 2016.

MIZRUCHI, M. S. Análise de redes sociais: avanços recentes e controvérsias atuais. Revista de Administração de Empresas, São Paulo, v. 46, n. 3, p. 10-15, 2006. Disponivel em: <http://www.scielo.br/pdf/rae/v46n3/v46n3a13.pdf $\geq$. Acesso em: $1^{\circ}$ jul. 2016.

MONTEIRO NETO, F. F. Identidades migratórias. Revista de Psiquiatria Clínica. São Paulo, v. 6, n. 2, p. 113-128, 1985. 
Preditores da saúde mental em adolescentes de familias imigrantes em Portugal. In: MONTEIRO NETO, F. F. Estudos de psicologia intercultural: nós e outros. Lisboa. Fundação Calouste Gulbenkian, 2012. v. 2. P 13 - 43.

PEIXOTO, J.; EGREJA, C. A força dos laços fracos: estratégias de emprego entre os imigrantes brasileiros em Portugal. Tempo Social, São Paulo, v. 24, n. 1, p. 263282, 2012. Disponivel em: <http://dx.doi.org/10.1590/S010320702012000100013>. Acesso em: 10 jul. 2016.

PEIXOTO, J.; FIGUEIREDO, A. Imigrantes brasileiros e mercado de trabalho em Portugal. In: MALHEIROS, J. M. (Org.). Imigração brasileira em Portugal. Lisboa: ACIDI, 2007. p. 87-111. (Coleção Comunidade, n. 1).

SERVIÇO de Estrangeiros e Fronteiras - SEF. Relatório de Imigração, Fronteiras e Asilo. 2013. Disponivel em: <http://sefstat.sef.pt/Docs/Rifa_2013.pdf $\geq$. Acesso em: $1^{\circ}$ jul. 2016.

TAJFEL, H. Grupos humanos e categorias sociais. Lisboa: Horizonte, 1981.

VERMELHO, S. C.; VELHO, A. P. M.; BERTONCELLO, V. Sobre o conceito de redes sociais e seus pesquisadores. Educação e Pesquisa, São Paulo, ahead of print, 2015. Disponivel em: <http://www.scielo.br/pdf/ep/2015nahead/1517-9702-ep1517-97022015041612.pdf $\geq$. Acesso em: $1^{\circ}$ jul. 2016.

WALDMAN, T. C. Movimentos migratórios sob a perspectiva do direito à saúde: imigrantes bolivianas em São Paulo. Revista de Direito Sanitário, São Paulo, v. 12, n. 1, p. 90-114, 2011. Disponivel em:

<http://Www.justica.sp.gov.br/StaticFiles/SJDC/ArquivosComuns/ProgramasProj etos/NETP/Revista\%20de\%20Direito\%20Sanit.rio_vol.\%2012_n.\%201_01.pmd.pdf . Acesso em: 30 jun. 2016.

Recebido: 18 nov. 2016 Aceito: 20 set. 2018 